\title{
INVESTIGATING THE IMPACT OF THE UNIQUE BUSINESS ENVIRONMENT OF FARMING ON FARMING FAMILIES' WELL-BEING
}

\author{
Connar McShane, James Cook University, Australia \\ Frances Quirk, James Cook University, Australia \\ Anne Swinbourne, James Cook University, Australia
}

\begin{abstract}
Objectives. This study aimed to investigate the impact that the unique organisational structure of the farming business had on farming families' wellbeing. Due to a lack of research in the area and available relevant measures, this study is also part of a process to adapt, develop and validate measures of work-family conflict, stressors, and coping that are relevant for farming families of Australia. This presentation will show findings from the interview and item reduction stages of the study. Methods. Interviews $(N=53)$ were conducted and analysed using a combination of grounded theory and content analysis, predefined major categories with subcategories were generated from the interview data. The Item Reduction Study included participants from across Australia and involved a survey that asked participants to rate items for relevance and importance. Results. Support was found for both Spillover and Segmentation Theory in explaining conflict direction. Women were not committed to the farming business as much as their partners, suggesting a possible source of conflict. Farming families perceived the public and government as uncaring and unsupportive of farming issues. Despite adversity and stressors, farming families were generally satisfied with life and roles. Conclusions. The feelings of abandonment and perceived lack of care and support for farming families could have serious implications for farming families' mental health, the development of learned helplessness and contribute to the observed high suicide rates of male farmers. Furthermore, changes in policies that result in reduction of community connectedness and a sense of belonging could be augmenting the problem.
\end{abstract}

